amount of material assistance as well. A good deal of helpful interest was shown also by the staff of Gordon College and by private residents in Khartoum.

To an observer with some experience of pre-war eclipse expeditions from Great Britain, remarkable features of the recent eclipse. were the growth in size and elaboration of the instruments used, and the lavish scale of expenditure of some expeditions. As everyone who tries it soon discovers, to make a scientific instrument work well in the open air, exactly at a given time, under conditions which cannot be reproduced beforehand, and perhaps in an extreme climate too, is far more difficult than to use it in an ordinary laboratory. Increased complexity of eclipse instruments seems inevitable, as problems and techniques develop, and in consequence the demands upon eclipse observers can now be sometimes rather severe. One result, already apparent, is that the ratio of observers to instruments, sometimes less than unity before the War, is tending to increase to two or three or more, while, as already noticed, the time allowed for preparation on site is tending to get longer.

The other point is of more local significance. British expeditions are at present financed chiefly by Government grants from the Royal Society, made on the recommendation of the Joint Permanent Eclipse Committee of the Royal Society and the Royal Astronomical Society. These grants are very limited in amount and are quite inadequate when more than one expedition is proposed. It is no longer possible to look to private individuals for subsidies, while British universities in general have no funds from which any appreciable contribution can be made. At the recent eclipse the Greenwich parties were paid for by the Admiralty, but even with this included, British expenditure amounted to only about one per cent of the reputed American expenditure. The Joint Permanent Eclipse Committee does excellent work within its means, and it is not necessary that British eclipse funds should be increased a hundredfold-nor indeed is it likely that with such an increase the results would be related linearly to expenditurebut it is suggested that some means should be found of financing eclipse expeditions from Great Britain more liberally, especially now that radio astronomers are in the field as well as the traditional optical observers.

${ }^{2}$ Stratton, F. J. M., Nature, 168, 259 (1952).

\section{SANTIAGO RAMÓN Y CAJAL (1852-1934)}

$\mathrm{P}$

ROBABLY the greatest neurohistologist of his generation, Santiago Ramón y Cajal, son of a surgeon, was born in Petilla de Aragon a century ago, on May 1, 1852. After obtaining from the University of Zaragoza at the age of twenty-one a licence to practise medicine, he saw military service with the army medical corps in Cuba. In 1879 he was appointed director of the medical museum at Zaragoza, in 1883 professor of anatomy at Valencia, and in 1887 professor of histology and pathological anatomy at Barcelona. Five years later he was called to the corresponding chair at Madrid, from which he retired in 1922. For many years he was in charge of the Madrid Institute, which bears his name. His "Trabajos del Laboratorio de Investigaciones biológicas de la Universitad de Madrid" was influential in making known to the world the work of Spanish men of science.

In 1889 Ramón y Cajal improved Golgi's chromesilver stain, which he applied to the whole nervous system and which led to his doctrine of the neurones. Using a photographic technique, he showed that all nerve cells are discrete units and that the cells of the grey matter are not organized as a network, as had previously been assumed. His name has become attached to some six staining methods, to the olfactory area, to the commissural nucleus, and to the horizontal cells of the cortex. Among his other classic contributions to neurology may be mentioned his discovery of the optic chiasma and of the innervation of the retina; his elucidation of the histology of degeneration and regeneration of nerve tissue; his modernization of the study of gliomata; and his pioneer use of colour photography. Shortly before his death on October 17, 1934, Ramón y Cajal reviewed and re-edited his first work on the neurone. He supervised the translation of his most important books, and his "Histology of the Nervous System in Man and Vertebrates" remains to this day the most complete and eccurate account of the microscopic anatomy of the nervous system.

Ramón y Cajal's interests were wide. He was a talented artist, and his extra-professional writings, such as his "Charlas de café" (1920), reflect his philosophic bent, his humanity, and his Latin pessimism. He sought no honours, but regarded his election as a foreign member of the Royal Society of London and his Nobel Prize for Medicine and Physiology, which he shared with Golgi in 1906, as a tribute to Spanish scientific research.

A long obituary notice of Ramón y Cajal appeared in Nature of December 8, 1934, p. 871, contributed by "C. S. S.", initials which are easily recognized as being those of one of the 'immortals' of physiology who himself died but a short time ago.

\section{OBITUARIES}

Sir Charles Sherrington, O.M., G.B.E., F.R.S.

Sir Charles Sherrington, formerly Waynflete professor of physiology in the University of Oxford, and president during 1920-25 of the Royal Society, died on March 4 at the age of ninety-four. Among his many distinctions may be mentioned the Copley Medal (1927) and a Royal Medal (1905) of the Royal Society and the Nobel Prize for Medicine and Physiology in 1932 (with Prof. E. D. Adrian); he was an honorary or foreign member of many learned societies throughout the world.

We print below some appreciations which we have received.

MorE than forty years ago Sherrington published the Silliman Lectures he had given at Yale under the title "The Integrative Action of the Nervous System", and if he had published nothing after this he would still deserve to be reckoned one of the great physiologists. He gave us a new outlook on the nervous system by analysing its operations into their simplest elements and showing how these elements are welded together. The spinal reflex is taken as the starting point, and as Sherrington's chapters succeed one another the mechanism of sense organs and nerve 